\title{
Fail-Safe System Device
}

National Cancer Institute

\section{Source}

National Cancer Institute. Fail-Safe System Device. NCI Thesaurus. Code C50208.

A device designed to prevent malfunction, unsafe, or unauthorized operation of a device or system. 